\title{
IDENTIDADES LIQUIDADAS
}

\author{
José Szwako
}

É a "identidade" um problema sociológico? Se sim, desde quando? Que variáveis e dimensões sóciohistóricas ocupam o núcleo das práticas e das políticas identitárias? Através de um diálogo instigante com o jornalista italiano Benedetto Vecchi, o sociólogo polonês Zygmunt Bauman responde a essas questões ampliando o espaço de discussão sobre o tema da identidade, inserindo-o em sua teoria da era líquido-moderna. Neste novo arcabouço, categorias estabelecidas como "pertencimento", "comunidade", "reconhecimento" e "nacionalidade" são criticadas e analiticamente reposicionadas. Sob a influência de distintas chaves interpretativas de cunho filosófico e literário, a análise acompanha a diluição das identidades individual e coletiva no cenário fluido do mundo atual.

O caráter liquefeito da contemporaneidade, sua fluidez e volatilidade, segundo Bauman, constitui o traço mais explícito da singularidade de nossa modernidade. Isso, entretanto, é apenas a conseqüência de dois fatores que cruzados "liquefazem" e, por vezes, liquidam seus próprios processos e atores sociais: i) o abandono de uma ilusão moderna estabelecida: “[a] crença de que há um fim do caminho em que andamos, um telos alcançável da mudança histórica, um Estado (sic) de perfeição a ser atingido amanhã” (BAUMAN, 2001, p. 37) e ii) "a desregulamentação e a privatização das tarefas e deveres modernizantes" (idem, p. 38). É este o paradoxal cenário da modernidade líquida: os atores sociais, individualmente situados, além de experimentarem uma nova temporalidade, uma concepção de tempo e de futuro que os impede de um delineamento minimamente inteligível de "projetos de vida", são responsabilizados politicamente por suas escolhas ou trajetórias e, portanto, por suas conseqüências. Dentro desse quadro crítico, não é de surpreender que o tema da identidade seja central. Como se identificar numa sociedade fluida e composta por múltiplas redes? Que opções fazer se essas redes se fazem e se desfazem ao sabor da "trama global"?

Para responder a essas questões, dotado de imaginação sociológica e de uma clareza notória, Bauman observa que não é possível recorrer aos autores clássicos indagando o que é ou o quê constitui a "identidade", isso porque eles próprios não elaboraram estas questões enquanto tais. Além disso, explica ele, "esse súbito fascínio pela identidade, e não ela mesma, é que atrairia a atenção dos clássicos da Sociologia" (BAUMAN, 2005a, p. 23). Entretanto, se os clássicos não podem ajudar muito, o raciocínio do autor assume um tom de análise nitidamente simmeliano. Bauman tece seu argumento por meio de eventos quase anedóticos da vida cotidiana, dando carne e osso à dimensão psicossociológica e altamente patológica dos processos contemporâneos de identificação.

Como observa Bauman "é realmente um dilema e um desafio para a sociologia - se você lembrar de que, há apenas algumas décadas, a 'identidade' não estava nem perto do centro de nosso debate” (idem, p. 22-23). Para entrar no problema teórico da identidade, o autor revê a trajetória da noção partindo da concepção prémoderna de 'identidade nacional', essa 'ficção' que conseguiu incorporar, após um violento processo de investimento político e simbólico, a 'naturalidade' ao 'nascimento'. "A aparência de 'naturalidade' era tudo, menos 'natural'. [...] [A] naturalidade, e assim também a credibilidade do pertencimento declarado, só podia ser um produto final de antigas batalhas postergadas. $\mathrm{E}$ a sua perpetuação não podia ser garantida a não ser por meio de batalhas ainda por vir" (idem, p. 29). Ali, a identidade não era senão a luta pela imposição da identidade - se se quiser, a 'identidade nacional' nasce com o silenciamento de outros discursos, locais e regionais.

O cenário líquido-moderno, porém, não apenas engloba a questão da "identidade nacional" como a ultrapassa. Segundo o autor, processos como os de precarização dos padrões de emprego e rotinas de trabalho e "terceirização internacionalizada", junto ao retraimento das funções sociais do Estado, produzem níveis patológicos de insegurança e ansiedade, bem como uma desarticulação interna das demandas por políticas sociais. Estes níveis de insegurança, por sua vez, produziriam formas sociais neocomunitárias cuja ideologia tem base racista e xenófoba. É possível reconstruir o argumento em dois momentos principais: vê-se, primeiramente, um núcleo mais ou menos rígido composto pela tríade trabalho-Estado-atores. Num segundo momento, aparecem 
os efeitos perversos (insegurança e comunitarismo) advindos de uma combinação específica entre as partes desse núcleo. No espaço desta resenha, analisamos exclusivamente a primeira parte do raciocínio, apontando para o alcance da crítica de Bauman no que diz respeito às respectivas dimensões daquela tríade.

Primeiro, o mundo do trabalho. Inspirado pelas críticas de Richard Sennett à desregulamentação legal e cotidiana da dinâmica laboral, Bauman afirma que o local de trabalho - "onde [antes] o status social costumava ser definido" (idem, p. 36) - atualmente, além de inspirar pouca confiança, não deixa espaço para a identificação e a solidariedade grupais devido a sua flexibilização. Neste sentido, Bauman reproduz e reitera a seguinte idéia postulada por Sennett: "um local de trabalho flexível provavelmente não seria o lugar onde alguém desejaria construir um ninho" (SENNETT, 2002). Pode argumentar-se, porém, que o espaço e as condições de trabalho não são, e tampouco foram historicamente, o espaço ideal para construir algo como um lar. Ao enfatizar as novas formas de violência tipicamente líquidas - notadamente aquelas ligadas a eufemização necessária à violência contra a subjetividade, como por exemplo "recursos humanos" e "administração por objetivos" Bauman esquece-se dos exercícios tradicionais fortemente alienantes de violência laboral ${ }^{1}$. Não há, portanto, uma exclusividade, quanto à violência implicada e implícita na dinâmica produtiva da modernidade líquida. Tanto a citação de Sennett, quanto a comparação (trabalho-casa) não estão a altura da complexidade da tese, na medida em que o próprio Bauman percebe e reconhece como os problemas atuais de auto-identificação ultrapassam, em muito, a esfera produtiva.

Em segundo lugar, o papel do Estado. Talvez seja esse o ponto em que o autor dá, de fato, sua maior contribuição à teoria social, ao apontar para um novo grupo de atores sociais sem direito à identificação. Numa perspicaz operação intelectual que une Mary Douglas a Max Weber, o sociólogo polonês define a função política do Estado penal contemporâneo: "Trancafiar pedófilos, varrer das ruas os vagabundos, ociosos, mendigos e outros indesejáveis, e deter suspeitos de terrorismo antes que se transformem em terroristas de fato" (BAUMAN, 2005a, p. 52). Em outra obra, Vidas desperdiçadas, Bauman elabora uma definição mais concisa e sociológica postulando que "os Estados-nações atuais [...] ainda afirmam sua prerrogativa essencial de soberania básica: o direito de excluir" (BAUMAN, 2005b, p. 45). Aqui, sua crítica dá ênfase aos processos de privatização do espaço público, de criminalização global e, especialmente, de produção de 'lixo humano' um novo grupo de "“pessoas rejeitadas' - não mais necessárias ao perfeito funcionamento do ciclo econômico" (BAUMAN, 2005a, p. 47).

A terceira e última parte do argumento é também a mais controversa. Bauman critica os denominados novos atores ou movimentos sociais afirmando que "não existe um lar óbvio a ser compartilhado pelos descontentes sociais [...] os ressentimentos sociais estão órfãos [...] A guerra por justiça social foi portanto reduzida a um excesso de batalhas por reconhecimento" (idem, p. 41-3, sem grifos no original). $\mathrm{O}$ argumento do autor consiste em dizer que as "novas bandeiras" - leia-se "gênero, raça e heranças coloniais" (idem, p. 42) - com "âncoras sociais próprias" ao mesmo tempo em que se afundaram "numa proliferação de campos de batalha", esqueceram-se da "miséria" vivida pelo "lixo humano". No entanto, é válido questionar: como esse "refugo humano" é produzido? Estariam "gênero", "raça" e, sobretudo, "imaginários pós-coloniais" como que fora dessa produção coletiva? Porque a falta de um "lar óbvio" para as demandas sociais corresponderia à "redução" de tais demandas? Embora o autor não forneça explicações - necessárias - à altura do problema por ele formulado, ficam algumas pistas textuais para onde ele, indiretamente, aponta. Bauman sugere que essas novas bandeiras estariam dificultando tanto lutar, quanto pensar uma "solução universal e abrangente" (idem, p. 43). Como leitor declarado da obra de Pierre Bourdieu, o autor poderia questionar a existência de qualquer "lar óbvio" (dóxico) e suspeitar das "soluções universais" na medida em que, como se sabe, o "universal" não é senão a universalização do particular - nesse sentido, o exemplo da "ficção" da "naturalidade", essa ficção tornada "na única realidade imaginável” (idem, p. 26), já havia sido destacada pelo próprio Bauman.

Em certa medida, no que concerne à questão das "novas bandeiras", a visão de Bauman reproduz aquilo que Joan Scott chamou de "daltonismo racial", fenômeno que encerra as questões de raça na concepção de "negritude" "da mesma forma como o gênero era [limitado a] uma questão de mulheres e não de homens" (SCOTT, 2005, p. 25). O sociólogo polonês ao falar da fragmentação das lutas sociais a vê como sintoma de um declínio - para utilizar a expressão de Sennet - não restrito aos movimentos sociais, de caráter moral de "um mundo esvaziado de valores que finge ser duradouro" (BAUMAN, 2005a, p. 59) e cuja esfera político-pública

${ }^{1}$ Descrição exemplar das formas sólidas de violência laboral pode ser observada em Braverman (1977). 
é continuamente despolitizada porquanto particularizada: "O descontentamento social", diz ele, "dissolveu-se num número indefinido de ressentimentos de grupos ou categorias [...] todas eram cegas, ou pelo menos desconfiadas ou francamente hostis, a reivindicações semelhantes de exclusividade declaradas e ouvidas por outros" (idem, p. 42). Entretanto, como observa Joan Scott, parece ocorrer precisamente o oposto, à medida que em parte das sociedades democráticas ocidentais um número cada vez maior de atores sociais reivindica reconhecimento propriamente político em âmbito "universal", vale dizer, um reconhecimento dentro do domínio, no sentido matemático e político do termo, público, social e legal. "A idéia de que todos os indivíduos poderiam ser tratados igualmente inspirou aqueles que se encontravam excluídos do acesso a algo que eles $e$ suas sociedades consideravam um direito" (SCOTT, 2005, p. 17; sem grifos no original). Ou seja, ao contrário da visão daltônica de Bauman que não vê os movimentos sociais senão como meros "ressentimentos", é precisamente devido à e dentro da ideologia ocidental de traços universalizantes e universalizáveis que esses "grupos ou categorias" pretendem inscrever-se. Assim, na medida em que tais grupos têm suas identidades histórica e politicamente reconhecidas, de fato a esfera pública se fragmenta, democratizando-se porque complexificada e heterogênea, exigindo então outras perspectivas de análise.

Seguramente, esse processo não é simples. O próprio Bauman, apesar de em princípio problematizar a questão em termos redutores por meio da fórmula unidade versus diferença - "como alcançar a unidade (apesar da?) diferença e como preservar a diferença na (apesar da?) unidade" (BAUMAN, 2005a, p. 48) - é muito claro quanto ao que está em jogo nessas "batalhas por identidade". Para o autor, elas são "misturas de demandas 'liberais' pela liberdade de autodefinição e auto-afirmação" com "apelos "comunitários' a uma 'totalidade maior do que a soma das partes', bem como à prioridade sobre os impulsos destrutivos de cada uma das partes" (idem, p. 84). Aqui, a idéia de mistura entre a natureza das distintas demandas político-identitárias torna densa a compreensão daquilo que Scott denominou de "o enigma da igualdade". A compreensão da tensão entre as múltiplas identidades, para ambos, aponta necessariamente para a profunda ambivalência que ocupa o cerne das estratégias de reconhecimento: na medida mesma em que demandam reconhecimento identitário, ou seja, igualdade legal e legítima, tais estratégias reproduzem diferença. "Os termos do protesto contra a discriminação tanto recusam quanto aceitam as identidades de grupo sobre as quais a discriminação está baseada" (SCOTT, 2005, p. 20). Bauman, por sua vez, é mais assertivo: "As batalhas de identidade não podem realizar sua tarefa de identificação sem dividir tanto quanto, ou mais do que, unir. Suas intenções includentes se misturam com (ou melhor, são complementadas por) suas intenções de segregar” (BAUMAN, 2005a, p. 85). O cenário delineado pelo sociólogo polonês é liquidante.

No que concerne à identificação propriamente individual, o caráter fluido quer das relações sociais, quer dos quadros de ação social constitui, segundo o autor, um dos eixos centrais da patologização psíquica contemporânea. Por meio de exemplos tão inusitados quanto o amor hiperbólico de Don Juan de Molière, a relação com animais de estimação na Londres de hoje, ou as horas sem-fim ao celular, a análise de tom simmeliano enfatiza o abismo entre cultura subjetiva e cultura objetiva, destacando os efeitos do 'consumismo' na subjetividade liquidada. Também os casamentos e as relações interpessoais aparecem como quadros sociais nada sólidos na análise. "A maioria de nós", diz ele, "tem uma opinião ambígua sobre essa novidade que é 'viver livre de vínculos' - de relacionamentos 'sem compromisso' [...]. Não voltaríamos atrás, mas nos sentimos pouco à vontade onde estamos agora" (idem, p. 69). Talvez não esteja nessa temática o ponto mais forte de Bauman como sociólogo pois ele próprio parece não ultrapassar seu sentimento de estranheza com relação à fluidez dos laços líquido-amorosos e suas altas taxas de separação ou divórcio. Neste sentido, é sintomática a formulação pela qual sintetiza as dicas de "insensíveis especialistas" (idem, p. 73) em relacionamentos: "se você quer 'relacionar-se', mantenha distância. Se deseja obter satisfação com o convívio, não estabeleça nem exija compromissos" (idem, p. 74). Ao que tudo indica, o sociólogo polonês vê essa fluidez amorosa como uma contradição em termos. Entretanto, é possível observar que o distanciamento e o autocontrole emocionais exigidos como pré-condição para o estabelecimento de laços afetivos são um produto histórico da sociabilidade cortesã ${ }^{2}$ herdado pela sociedade burguesa. Historicamente, portanto, distanciamento e autocontrole não são uma particularidade das formas líquidas de relação, nem sequer constituem qualquer forma de negação ou fechamento das possibilidades de construção amorosa, sejam elas pós-modernas ou não.

\footnotetext{
2 Para uma análise da transformação histórica da coerção rumo a autocoerção, ver "Sobre a sociogênese do romantismo aristocrático no processo de curialização" (ELIAS, 2001).
} 
No seu todo, muito além de matizar distintos componentes e dimensões centrais na estruturação da identidade, o livro-diálogo oferece um lúcido e, sobretudo, crítico panorama da sociedade capitalista atual. É dentro da liquefação dos processos e laços sociais que Bauman entrelaça posições, trajetórias e estruturas sociais. Nesse emaranhado inseguro e imprevisível, a identidade não é construída com relação a fins ("Eu quero ser") nem tampouco com relação a meios ("Eu posso ser"). "Selecionar os meios necessários para conseguir uma identidade alternativa de sua escolha não é mais o problema", para Bauman, "o verdadeiro problema e atualmente a maior preocupação é a incerteza oposta: qual identidade escolher e [...] por quanto tempo se apegar a ela?" (idem, p. 91). O autor abandona o lugar-comum antropológico e vai ao cerne da questão: na modernidade líquida a identidade não é uma mera "construção social”; ter uma ou muitas identidades é uma tarefa, ou mais precisamente, uma tarefa política.

José Szwako (jszwako@bol.com.br) é Mestre em Sociologia pela Universidade Federal do Paraná (UFPR) e professor da mesma instituição.

\section{REFERÊNCIASBIBLIOGRÁFICAS}

BAUMAN, Z. 2001. Modernidade líquida. Rio de Janeiro : J. Zahar. .2005a. Identidade : entrevista a Benedetto Vecchi. Rio de Janeiro : J. Zahar. . 2005b. Vidas desperdiçadas. Rio de Janeiro : J. Zahar.

BRAVERMAN, H. 1977. Trabalho e capital monopolista. Rio de Janeiro : J. Zahar.

ELIAS, N. 2001. A sociedade de corte. Rio de Janeiro : J. Zahar.

SCOTT, J. 2005. O enigma da igualdade. Estudos Feministas, Florianópolis, v. 13, n.1, p. 11-30, abr.

SENNETT, R. 2002. Flexibilité sur la ville. Maniere de Voir, Paris, n. 66, p. 59-62, nov.-dec. 